Artigo

\title{
A educação matemática e a fórmula n-1: rizoma e utopia
}

\author{
Mathematical education and the $\mathrm{n}-1$ formula: rhizome and utopia \\ Educación matemática y la fórmula n-1: rizoma y utopía
}

\author{
José Rogério Vitkowski ${ }^{1}$ \\ [0000-0002-4821-9576]
}

\section{Resumo}

Este texto aborda a educação matemática enquanto plano de imanência ancorado no referencial da filosofia da diferença ou multiplicidade, na vertente deleuze-guattariana, acrescido das observações da prática educativa do autor. O legado dos filósofos apregoa que a atividade filosófica se caracteriza como potência do pensamento humano, com a finalidade primordial de criação de conceitos. Nessa perspectiva, os conceitos filosóficos não estão prontos nem acabados. Por meio de uma pedagogia do conceito e de procedimentos de desterritorialização e reterritorialização, é possível pensar filosoficamente. Dispomo-nos aqui, portanto, a realizar um exercício de pensamento que intenta estabelecer conexões entre a filosofia e a educação matemática, considerando a fórmula n-1. Esta fórmula se situa num amplo lócus epistêmico que remete a considerar a constituição e a crise de um paradigma científico denominado de cartesiano-newtoniano. A metáfora principal que traduz esse paradigma é a de um conhecimento de tipo arbóreo, tomado como uma grande árvore cujas raízes devem ficar assentadas em terreno firme, com um tronco que se ramifica em galhos. Essa metáfora representa uma concepção mecânica do conhecimento, reproduzindo a fragmentação cartesiananewtoniana do saber. Esse paradigma arborescente produz, portanto, uma fortíssima hierarquização do conhecimento, que tem sido questionada veementemente por vasta comunidade científica. Epistemologicamente falando, atravessamos uma crise paradigmática que tem sido problematizada por pesquisadores de diferentes matrizes teóricas, dentre eles, Deleuze e Guattari, que nos apresentam o interessante conceito de rizoma como contraposição ao modelo arbóreo. Uma educação rizomática é a proposta inspiradora para o desenvolvimento de pautas relacionadas à educação matemática.

Palavras-chave: Filosofia da Diferença. Educação Matemática. Rizoma.

\section{Abstract}

This text addresses mathematical education as a plan of immanence anchored in the referential of the philosophy of difference or multiplicity, in the Deleuze-Guattarian aspect, plus the observations of the author's educational practice. The legacy of philosophers claims that philosophical activity is characterized as a power of human thought, whose primary purpose is the creation of concepts. In this perspective, philosophical concepts are neither ready nor finished. Through a pedagogy of the concept and procedures of deterritorialization and reterritorialization, it is possible to think philosophically. Therefore, we are ready to carry out a thought exercise that attempts to establish connections between philosophy and mathematical education, considering the formula $n-1$. This formula is located in a broad epistemic locus that leads us to consider considering the constitution and crisis of a scientific paradigm called Cartesian-Newtonian. The main metaphor that translates this paradigm is that of arboreal knowledge, which is taken as a large tree, the roots of which must lie on firm ground, with a trunk that branches into branches. This metaphor represents a mechanical conception of knowledge, reproducing the Cartesian-Newtonian fragmentation of knowledge. This arborescent paradigm,

1 jrvitkowski@gmail.com, doutor, professor adjunto, Universidade Estadual de Ponta Grossa, Ponta Grossa/PR/Brasil. 
therefore, produces a very strong hierarchy of knowledge, which has been questioned vehemently by a vast scientific community. Epistemologically speaking, we are going through a paradigmatic crisis that has been problematized by researchers from different theoretical matrices, among them, Deleuze and Guattari, who present us with the interesting concept of rhizome as a counterpoint to the tree model. Rhizomatic education is the inspiring proposal for the development of guidelines related to mathematical education.

Keywords: Philosophy of Difference. Mathematical Education. Rhizome.

\section{Resumen}

Este texto aborda la educación matemática como un plan de inmanencia anclado en el referencial de la filosofía de la diferencia o multiplicidad, en el aspecto deleuze-guattariano, más las observaciones de la práctica educativa del autor. El legado de los filósofos afirma que la actividad filosófica se caracteriza por ser un poder del pensamiento humano, cuyo propósito principal es la creación de conceptos. En esta perspectiva, los conceptos filosóficos no están ni listos ni terminados. A través de una pedagogía del concepto y los procedimientos de desterritorialización y reterritorialización, es posible pensar filosóficamente. Por tanto, estamos preparados para realizar un ejercicio de pensamiento que intenta establecer conexiones entre filosofía y educación matemática, considerando la fórmula n-1. Esta fórmula se ubica en un amplio locus epistémico que nos lleva a considerar la constitución y crisis de un paradigma científico denominado cartesiano-newtoniano. La principal metáfora que traduce este paradigma es la del conocimiento arbóreo. El conocimiento se toma como un gran árbol, cuyas raíces deben reposar en suelo firme, con un tronco que se ramifica en ramas. Esta metáfora de la botánica representa una concepción mecánica del conocimiento, reproduciendo la fragmentación cartesiano-newtoniana del conocimiento. Este paradigma arborescente, por tanto, produce una jerarquía de conocimiento muy fuerte, que ha sido cuestionada con vehemencia por una vasta comunidad científica. Epistemológicamente hablando, estamos atravesando una crisis paradigmática que ha sido problematizada por investigadores de diferentes matrices teóricas, entre ellos, Deleuze y Guattari quienes nos presentan el interesante concepto de rizoma como contrapunto al modelo del árbol. La educación rizomática es la propuesta inspiradora para el desarrollo de pautas relacionadas con la educación matemática.

Palabras claves: Filosofía de la diferencia. Educación Matemática. Rizoma.

Este texto aborda a educação matemática enquanto plano de imanência e tem como ancoragem metodológica a filosofia da diferença proposta pelos filósofos franceses Deleuze e Guattari. Em sintonia com os pensadores, a abordagem da filosofia da diferença se debruça no movimento da multiplicidade e não da unidade. É uma filosofia que se contrapõe ao pensamento representacional, ao pensamento arbóreo ou radicular.

A obra dos filósofos supracitados compreende um esforço de crítica a um tipo de pensamento designado de representação e é entendida como constituição de uma filosofia da diferença ou da multiplicidade - ou do acontecimento (ALLIEZ, 1996). Tanto a crítica à representação quanto a construção de uma filosofia da diferença são duas faces de um mesmo movimento do pensamento, que, na obra deleuziana, se desdobram num universo de vasto repertório teórico, no qual importa arrancar a diferença de seu estado de maldição, ou, mais precisamente, nas palavras de Deleuze: "tirar a diferença de seu estado de maldição parece ser, pois, a tarefa da filosofia da diferença" (DELEUZE, 2006, p. 57).

O legado dos filósofos apregoa que a atividade filosófica, assim como a arte e a filosofia, se caracteriza como potência do pensamento humano. Cabe à filosofia uma 
finalidade primordial, a saber, a criação de conceitos (DELEUZE; GUATTARI, 1997). Nesse contexto, os conceitos filosóficos não estão nem prontos nem acabados. Por meio de uma pedagogia do conceito e de procedimentos de desterritorialização e reterritorialização, é possível pensar filosoficamente (GALLO, 2008). Portanto, é a partir desse lócus epistêmico, desdobrado em vasto universo nocional, que nos situamos neste texto.

Importante registrar que Deleuze, ao pensar sobre a Universidade de Vincennes, manifestava sua preocupação de saber "em que" a filosofia pode servir a matemáticos ou a músicos etc., mesmo quando ela não fala de música ou de matemática. Assim, a indicação do filósofo era de que o ensino não colocasse entre parênteses os saberes de outras disciplinas; ao contrário, a filosofia deve ter uma tonalidade prática, experimental, "algo que interesse" a um público frequentemente heterogêneo e de distintos níveis de compreensão, idade, afinidades. Essa exterioridade e suas ressonâncias devem ser acolhidas pela filosofia e pelo educador, pois "é de grande interesse pedagógico, ao contrário, jogar no interior de cada disciplina essas ressonâncias entre níveis e domínios de exterioridade" (DELEUZE, 2002).

Registramos que este texto se nutre também das inquietações de nossa experimentação docente enquanto professor na área de fundamentos da educação atuando nas licenciaturas, dentre elas, na licenciatura em matemática.

Esclarecemos que o campo de conhecimento dos fundamentos da educação se apresenta articulado pelos saberes de diversas ciências, entre as quais a história, a sociologia, a psicologia e, com destaque, a filosofia. Essa diversidade de saberes compõe um cenário diferenciado para o trato das questões educacionais e se articula com a educação matemática compreendida como um paradigma de formação transdisciplinar, multicultural.

Habitamos, portanto, a dinâmica fora-dentro, dentro-fora, como mirante de experimentação, de observação e de produção deste texto. Com efeito, a cada ano nos defrontamos, juntamente com outros docentes e alunos, com os "nós" da educação, que também são "nós" da educação matemática.

Percebemos que temas e problemas pedagógicos se misturam ao metodológico, ao histórico; desembocam no filosófico. Por exemplo, recorrentemente nos inquietamos com a difícil articulação entre a matemática enquanto ciência e as questões filosófico-formativas de futuros professores.

Uma questão que permanece desafiadora através dos anos se refere à compartimentalização do conhecimento e de saberes entre as disciplinas. Continuamos a dividir o conhecimento em gavetas e dificilmente conseguimos articular os conhecimentos entre si e com outras esferas e campos do conhecimento humano.

Dito de forma bastante simples, observamos como os alunos, futuros professores, se dedicam sofridamente a assimilar um rol de saberes específicos de trigonometria, álgebra, geometria, complexos cálculos de todo tipo, mas não conseguem inter-relacionar - ou têm extrema dificuldade - os conhecimentos, seja com os processos de ensino-aprendizagem básicos que deverão desenvolver no chão batido da escola, seja relacionar a matemática com perspectivas mais amplas de problemas que envolvem o mundo, a sociedade, o cidadão. Evidentemente, não podemos tratar de forma individualizada o leque de questões que daí procedem. Todavia, elas formam um cenário, um buquê de interrogações martelantes e que nos remetem a pensá-las epistemicamente, isto é, filosoficamente.

Dispomo-nos aqui, portanto, a realizar um exercício de pensamento que intenta estabelecer conexões entre os dois campos, a filosofia e a educação matemática, considerando a fórmula $\mathrm{n}-1$. Para isso, dialogamos prioritariamente com os textos dos 
filósofos franceses Gilles Deleuze e Félix Guattari, com acréscimo das contribuições do filósofo brasileiro Silvio Gallo, cujas incursões e produção de conceitos já se tornaram referência para a abordagem a que nos propomos. Também contamos com os trabalhos de Tomás Tadeu da Silva (2005), Daniela Schneider (2014), dentre outros.

\section{N-1: eis a fórmula!}

Aqui se faz necessário um gesto deflagrador. Por onde começar, entretanto? Tomás Tadeu da Silva (2002, p. 48) sugeriu o seguinte encaminhamento: "Pelo meio, claro, por onde mais? Quer dizer, por qualquer lugar, inclusive pelo começo".

Clarice Lispector tece um belíssimo comentário à palavra "começo":

Tudo no mundo começou com um sim. Uma molécula disse sim a outra molécula e nasceu a vida. Mas antes da pré-história havia a pré-história da pré-história e havia o nunca e havia o sim. Sempre houve. Não sei o quê, mas sei que o universo jamais começou (LISPECTOR, 1998).

Consideremos então que, na atividade de interpretação do mundo, o ser humano, homo sapiens, construiu todo um complexo paradigma de conhecimento. Em traços gerais, podemos afirmar que, antes de 1500, a visão de mundo que prevalecia na Europa da Idade Média era a visão de mundo teocêntrica. O pensamento hegemônico se assentava na fundamentação platônico-agostiniana e depois na aristotélica-tomista, que consideravam de maior significância as questões referentes a Deus, à alma humana e à ética. O objetivo principal da filosofia era servir de base à teologia e tinha como causa de suas preocupações a salvação da alma após a morte. Foi um período de contemplação do universo, de respeito às autoridades constituídas, de hipervalorização dos textos bíblicos e gregos.

A partir dos séculos XVI e XVII, a natureza da ciência medieval sofre mudanças radicais, num período que ficou conhecido como Revolução Científica. Sobre essa etapa da história da ciência, acontecida nos séculos XVI e XVII, Reale e Antiseri (1990, p. 185) estabelecem, na história da Filosofia, a relação dos seus principais personagens:

O período de tempo que vai mais ou menos da data de publicação do Revolutionibus, de Nicolau Copérnico, isto é, de 1543, à obra de Isaac Newton, Philosophiae naturalis principia mathematica ${ }^{2}$ que foi publicada pela primeira vez em 1687, hoje é comumente apontado como o período da "revolução científica". Trata-se de um poderoso movimento de ideias que adquire no século XVII as suas características determinantes na obra de Galileu, que encontra os seus filósofos - em aspectos diferentes - nas ideias de Bacon e Descartes e que depois iria encontrar a sua expressão agora clássica na imagem newtoniana do universo concebido como uma máquina, ou seja, como um relógio.

Esse período da história humana tem profundas repercussões em vários planos. Não é apenas a imagem do mundo que se transforma. Junto a essa transformação, ocorre também a mudança das ideias sobre o homem, sobre o trabalho científico e as instituições científicas, sobre as relações entre ciência e fé religiosa.

Tomando como referência os autores mencionados, sintética e esquematicamente, as questões levantadas pela revolução científica podem assim ser explicitadas:

\footnotetext{
2 Princípios matemáticos da filosofia natural.
} 
a) Copérnico tira a Terra do centro do universo e, com ela, o homem. A terra não é mais o centro do universo, mas um corpo celeste como os outros: ela, precisamente, não é mais aquele centro do universo criado por Deus em função de um homem concebido como o ponto mais alto da criação, em função do qual estaria todo o universo.

b) Mudando a imagem do mundo, muda a imagem do homem. Mas também, progressivamente, muda a imagem da ciência. A revolução científica não consiste somente em adquirir teorias novas e diferentes das anteriores sobre o universo astronômico, sobre a dinâmica, sobre o corpo humano ou, talvez, sobre a composição da Terra. Ao mesmo tempo, a revolução cientifica é uma revolução da ideia de saber e de ciência.

c) Com a revolução científica, abriu-se caminho para as categorias, os métodos, as instituições, os modos de pensar e os valores relacionados com aquele fenômeno que, depois da revolução científica, costumamos chamar de ciência moderna. E o traço mais característico desse fenômeno resume-se precisamente no método.

d) Juntamente com a cosmologia aristotélica, a revolução científica leva à rejeição das categorias, dos princípios e das pretensões essencialistas da filosofia aristotélica. $\mathrm{O}$ antigo saber pretendia ser saber de essências, ciência feita de teorias e conceitos definitivos. [...] Ou seja: a ciência não está mais voltada para a essência ou substância das coisas e dos fenômenos, mas sim para a qualidade das coisas e dos acontecimentos de modo objetivo, e, portanto, sendo comprováveis e quantificáveis publicamente. Não é mais o que, mas o como; não é mais a substância, mas sim a função que a ciência galileana e pós galileana passariam a indagar (REALI; ANTISERI, 1990, p. 185s).

Desse modo, a revolução científica transforma a maneira de construir o conhecimento científico, colocando o método como centro da ciência moderna.

Desde então, e para os objetivos deste texto, assinalamos que o paradigma cartesianonewtoniano tem se constituído como referência absoluta para a produção científica que se estende até nossos dias. De fato, experimentamos até hoje o benefício e os limites desse modelo.

A metáfora principal que traduz esse paradigma é a de um conhecimento de tipo arbóreo. O conhecimento é tomado como uma grande árvore, cujas raízes devem ficar assentadas em terreno firme, com um tronco que se ramifica em galhos. Essa metáfora da botânica representa uma concepção mecânica do conhecimento, reproduzindo a fragmentação cartesiana-newtoniana do saber.

Notemos que o tronco da árvore do conhecimento se deu em torno da filosofia. E os galhos se constituíram como ciências derivadas, que se relacionam com um tronco comum. Um nó problemático que compõe o desenvolvimento científico foi a expansão do conhecimento por meio de uma disciplinarização, ou seja, da delimitação de campos específicos para cada forma de se abordar um determinado aspecto da realidade, cada um se constituindo numa disciplina autônoma.

Esse paradigma arborescente produz, portanto, uma fortíssima hierarquização do conhecimento, que tem sido questionada veementemente por vasta comunidade científica. Epistemologicamente falando, hoje atravessamos uma crise paradigmática que tem sido problematizada por pesquisadores de diferentes matrizes teóricas, mais recentemente, com Boaventura de Souza Santos (1998; 2004), Fritjof Capra (2012), Edgar Morin (2014), dentre outros. 
Segundo esses autores estamos vivendo num período de transição muito importante na história humana, um período de diversos desafios que ocorrem simultaneamente. 0 mais grave é que esses desafios envolvem diferentes dimensões - políticas, intelectuais, culturais, éticas - da sociedade e afetam os diferentes aspectos de nossa vida no planeta, dentre outros, o meio ambiente, a economia, o trabalho, a política e, portanto, a educação.

Esses diferentes desafios têm solicitado a restauração do diálogo crítico e criativo entre o homem e o mundo da natureza, entre ciência e sociedade. Os inúmeros problemas existentes hoje, segundo os autores, só podem ser resolvidos a partir da revisão, concorrência ou superação paradigmática.

O paradigma arborescente aporta uma concepção mecânica do conhecimento e da realidade, reproduzindo a fragmentação do saber, resultado das concepções científicas modernas estruturadas em hierarquias de conhecimento e com fronteiras e regiões de domínio praticamente instransponíveis.

Não é necessário nenhum grande esforço para perceber como essa fragmentação adentrou os espaços educacionais e a educação matemática: cursos com disciplinas estanques, hierarquias rígidas de conhecimentos disciplinarizados. $O$ resultado se traduz numa concepção de triste ciência que quantifica, tudo divide, tudo segmenta.

O filósofo Gilles Deleuze travou um embate duro com a segmentação moderna. Para ele, somos segmentarizados por todos os lados e em todas as direções. A segmentaridade pertence a todos os estratos que nos compõem.

Habitar, circular, trabalhar, brincar: o vivido é segmentarizado espacialmente e socialmente. A casa é segmentarizada conforme a destinação de seus cômodos; as ruas, conforme a ordem da cidade; a fábrica, conforme a natureza dos trabalhos e das operações (DELEUZE; GUATTARI, 1996, p. 84).

A crença de que a segmentarização garantiria mais objetividade às análises fez com que a ciência fosse altamente valorizada na modernidade e, por se crer em uma suposta neutralidade do conhecimento, produziu uma crença correlata de descompromisso ético. Da modernidade, herdamos a fé de que somos independentes das coisas que produzimos e que os juízos científicos são "verdadeiros e objetivos".

No período moderno, com a "invenção da ciência" e a criação do método científico, todos os saberes passam por uma assepsia. A purificação do mundo foi um empreendimento da modernidade que até hoje tem reflexos em nossos corpos e nossas vidas. Tudo o que pode ganhar estatuto de verdade deve ser dividido, quantificado e classificado dentro de um campo determinado do saber. São conhecidas as polarizações que advêm desse movimento, isto é, as divisões sujeito/objeto, homem/natureza se dão por uma sobreposição do espírito em relação ao corpo, assim como pela cientificização e objetivação da compreensão do mundo.

Um instigante texto deleuziano funciona concomitantemente como alerta, lamento e convite:

Não devemos mais acreditar em árvores, em raízes ou radículas, já sofremos muito. Toda a cultura arborescente é fundada sobre elas, da biologia à linguística. Ao contrário, nada é belo, nada é amoroso, nada é político a não ser que sejam arbustos subterrâneos e as raízes aéreas o adventício e o rizoma (DELEUZE; GUATTARI, 2011, p. 34). 
Diríamos, hoje, que já sofremos muito com os discursos de cunho essencialista, mas também com as propostas cientificistas que intentam explicações unitárias, arborescentes sobre o mundo, a sociedade, a educação, e que se expressam em jargões recorrentes valendose do verbo ser: é o mercado, é o capitalismo, é o sindicato, é a universidade, é o neoliberalismo, é o progresso, é a ciência!

Nesse amplo contexto, emerge o esforço da ampla comunidade filosófica e científica de se buscar um outro paradigma de conhecimento, uma nova imagem do pensamento que nos permita, como apregoa Gallo (2008, p. 75): “de novo, pensar, para além da fossilização imposta pelo paradigma arbóreo e pela consequente arborização de nosso pensamento".

Deleuze e Guattari, em Mil Platôs, apresentam o conceito de rizoma. Os filósofos tratam da questão do livro e recusam a organização do livro-raiz, no qual a árvore (ou a raiz) é a imagem do mundo. Na imagem-mundo arbórea, de centro hierárquico central, prevalece uma lógica problemática: a lógica binária. De acordo com Deleuze, "o livro, como realidade espiritual, a árvore ou a raiz como imagem não para de desenvolver a lei do Uno que devém dois, depois dois que devêm quatro... A lógica binária é a realidade espiritual da árvore-raiz". (DELEUZE; GUATTARI, 2011, p. 20).

Ora, por meio dessa lógica, acentuam-se os mecanismos do pensamento fundamentacionista, representacional, que permanentemente evoca o uno, o centro unitário fixo e de rigidez, no qual se pretende domesticar a multiplicidade. A imagem-mundo arbórea relaciona-se com um pensamento que nunca compreendeu a multiplicidade.

Portanto, para contrapor-se a esse modelo de pensamento, da imagem-mundo arbórea, Deleuze e Guattari propõem a transgressora noção de rizoma.

Em botânica, chama-se rizoma a um tipo de caule de algumas plantas verdes que cresce horizontalmente, muitas vezes subterrâneo, mas podendo também ter porções aéreas. Os caules do lírio e da bananeira são totalmente subterrâneos, mas certos fetos desenvolvem rizomas parcialmente aéreos. Certos rizomas, como em várias espécies de capim (gramíneas), servem como órgãos de reprodução vegetativa ou assexuada, desenvolvendo raízes e caules aéreos nos seus nós.

O rizoma expressa as multiplicidades sem ter que ligá-las à unidade ou a um princípio unitário. Ao invés de submeter a multiplicidade à unidade, deve-se extrair o uno da multiplicidade, como afirmam os filósofos:

Na verdade não basta dizer Viva o múltiplo, grito de resto difícil de emitir. Nenhuma habilidade tipográfica, lexical ou mesmo sintática será suficiente para fazer ouvi-lo. É preciso fazer o múltiplo, não acrescentando sempre uma dimensão superior, mas, ao contrário, da maneira simples, com força de sobriedade, no nível das dimensões de que se dispõe, sempre $n-1$ (é somente assim que o uno faz parte do múltiplo, estando sempre subtraído dele). Subtrair o único da multiplicidade a ser constituída; escrever a n-1. Um tal sistema poderia ser chamado de rizoma (DELEUZE; GUATTARI, 2011, p. 21).

Para os autores supracitados, até mesmo a maneira de se nomear as diferenças como "O Múltiplo" já indicaria a subordinação da multiplicidade a uma forma unitária. O artigo definido "o" é reducionista, limita as singularidades, remetendo-as à identidade. Ora, as singularidades podem ser pensadas a partir do artigo indefinido "um", pois este não fecha as portas para outros encontros, agenciamentos, conexões, afinal, "[u]m é sempre o índice de uma multiplicidade: um acontecimento, uma singularidade, uma vida" (DELEUZE, 2002, p. 41). 
É nessa circunscrição que se propõe o rizoma como uma nova produção, acêntrica, não hierárquica, do conhecimento. Ainda que se deva considerar que um rizoma não possui uma estrutura definida, pois com isso estaria se estabelecendo o aprisionamento arbóreo, é possível entrever os princípios de um rizoma. Sucintamente, para não nos estendermos demasiado, citamos: princípio da conexão, da heterogeneidade, da multiplicidade, da ruptura a-significante, da cartografia e da decalconomia.

Retomando Deleuze e Guattari (2011, p. 22-49), em Mil Platôs, resumimos as características desses princípios em forma de tópicos, ainda que comportem incompletudes.

\section{Princípios de conexão e heterogeneidade}

Diferentemente das árvores ou de suas raízes, o rizoma conecta um ponto qualquer com outro ponto qualquer e cada um de seus traços não remete necessariamente a traços da mesma natureza. De acordo com os filósofos:

Qualquer ponto do rizoma pode ser conectado a qualquer outro e deve sêlo. Cada traço não remete necessariamente a um traço linguístico: cadeias semióticas de todas as naturezas são aí conectadas, a modos de codificação muito diversos, cadeias biológicas, políticas, econômicas, etc... colocando em jogo não somente regimes de signos diferentes, mas também estatutos de estados de coisas (DELEUZE; GUATTARI, 2011, p.22).

Esses princípios podem ser relacionados com a complexidade do conhecimento contemporâneo. As coisas se relacionam. Pensar em alguma coisa implica estabelecer relações com múltiplos elementos e em diversos aspectos. No limite, podemos afirmar que tudo se relaciona com tudo. Ao tratar de algo, estamos criando conexões, ligações, pontes de comunicação. Note-se que a educação matemática é um terreno fértil para conexões marcadas por heterogeneidade de conhecimentos, de conteúdos, de professores, de metodologias.

\section{Princípio da multiplicidade}

O rizoma é sempre multiplicidade que não se deixa reconduzir nem ao Uno nem ao múltiplo. Ele não tem começo nem fim, mas sempre um meio pelo qual cresce e transborda. Constitui multiplicidades lineares a $n$ dimensões.

De acordo com Deleuze e Guattari (2011, p. 23):

Uma multiplicidade não tem nem sujeito, nem objeto, mas somente determinações, grandezas, dimensões que não podem crescer sem que se mude de natureza [...]. Um agenciamento é precisamente este crescimento das dimensões numa multiplicidade que muda necessariamente de natureza à medida que ela aumenta suas conexões.

Uma tal multiplicidade rizomática implica, portanto, num movimento de desenvolvimento inusitado.

As multiplicidades são definidas pelo fora, pelo movimento de desterritorialização, a partir do qual mudam de natureza ao se conectarem com outras. As multiplicidades só crescem se mudam de natureza. São conjuntos de variáveis postas em variação. Uma multiplicidade "é composta de dimensões que se englobam umas às outras, cada uma 
recapturando todas as outras em um outro grau, segundo uma lista aberta que pode ser acrescida de novas dimensões" (ZOURABICHVILI, 2004, p. 38).

\section{Princípio de ruptura a-significante}

O rizoma não supõe qualquer processo de significação ou de hierarquização. Um rizoma pode ser rompido, quebrado em um lugar qualquer e também retorna segundo uma ou outra de suas linhas e segundo outras linhas: linhas de segmentaridade, de estratificação como dimensões, mas também como linhas de fuga ou de desterritorialização. Uma ideia, um conceito, um saber, podem ser desterritorializados, ressignificados e conectados a outras concepções que satisfaçam a necessidade de produção conceitual.

Conforme os filósofos franceses:

Um rizoma pode ser rompido, quebrado em um lugar qualquer, e também retoma segundo uma ou outra de suas linhas [...] Todo rizoma compreende linhas de segmentaridade segundo as quais ele é estratificado, territorializado, organizado, significado, atribuído, etc.., mas compreende também linhas de desterritorialização pelas quais ele foge sem parar [...] essas linhas não param de remeter umas às outras (DELEUZE; GUATTARI, 2011, p. 25-26).

Essas indicações, em registro rizomático, nos mostram que as ciências conjugam fluxos desterritorializados, isto é, a ciência não se limita e funciona apenas em território determinado hierarquicamente. O rizoma, embora seja estratificado por linhas, está sempre sujeito às linhas de fuga, que apontam para novas direções e conexões. Cabe aqui referenciarmos o clássico texto sobre a vespa e a orquídea.

A orquídea se desterritorializa, formando uma imagem, um decalque de vespa; mas a vespa se reterritorializa sobre esta imagem. A vespa se desterritorializa, no entanto, tornando-se ela mesma uma peça no aparelho de reprodução da orquídea; mas ela reterritorializa a orquídea, transportando o pólen. A vespa e a orquídea fazem rizoma em sua heterogeneidade (DELEUZE; GUATTARI, 2011, p. 26).

Não mais imitação, nem semelhança, conforme os autores, mas captura de código, em que duas séries heterogêneas compõem um rizoma comum, ao qual não pode ser atribuído nenhum tipo de significante. Portanto, a relação da orquídea com a vespa não é de hierarquia, evolução, muito menos de imitação. O que se tem é o devir orquídea da vespa e vice-versa.

Para os autores (2011a, p. 29): "um rizoma não pode ser justificado por nenhum modelo estrutural ou gerativo. Ele é estranho a qualquer ideia de eixo genético ou de estrutura profunda". Essa imagem de eixo ou de estrutura está vinculada ao modelo arbóreo, se vincula à cópia, ao estático. No entanto, isto não significa que na estrutura rizomática não seja também considerada a possibilidade de árvores, campos específicos e hierárquicos do conhecimento. Eles existem como momentos. Desse modo, a investigação de uma dada área do conhecimento pode ser realizada com a perspectiva prevista na metáfora da árvore, para alcançar determinados objetivos. Não se deve esquecer, todavia, que a árvore articula e hierarquiza os decalques, que são como folhas da árvore. Em sintonia com os filósofos:

Diferente é o rizoma, mapa e não decalque. Fazer o mapa, não o decalque. A orquídea não reproduz o decalque da vespa, ela compõe um mapa com a 
vespa no seio de um rizoma. Se o mapa se opõe ao decalque é por estar inteiramente voltado para uma experimentação ancorada no real (DELEUZE; GUATTARI, 2011, p. 30).

Daqui decorrem os dois últimos princípios do rizoma descritos pelos filósofos franceses, a saber, o de cartografia e decalcomania.

\section{Princípio de cartografia}

O rizoma procede por uma lógica do devir, da variação, da expansão, da captura, da descoberta. Oposto aos decalques, o rizoma se refere a um mapa que deve ser produzido, construído, sempre desmontável, conectável, reversível, modificável, com múltiplas entradas e saídas, podendo remeter a qualquer outro ponto em seu território. Desse modo, produzir um mapa da educação matemática implica em estar atento aos seus movimentos, devires que são produzidos continuamente.

\section{Princípio de decalcomania}

Os mapas podem ser copiados, reproduzidos, porém colocar uma cópia sobre o mapa nem sempre garante uma sobreposição apropriada. O inverso é a novidade, ou seja, colocar o mapa sobre as cópias. É preciso referir os decalques aos mapas, e não o inverso. De acordo com os filósofos: "Contra os sistemas centrados (e mesmo policentrados) de comunicação hierárquica e ligações preestabelecidas, o rizoma é um sistema acentrado, não hierárquico, e não significante, sem general, sem memória organizadora ou autômato central" (DELEUZE; GUATTARI, 2011, p. 43).

O decalque é a cópia, a imitação do movimento. O decalque é a transferência de uma imagem, de uma forma, de um modelo, para uma superfície. E essa superfície pode - talvez deva - ser entendida como a superfície das ações. Decalcar é interiorizar, e não abrir. É reproduzir algo que já foi e que se mantém pelo próprio ato do decalque. O decalque já traduziu o mapa em imagem, já transformou o rizoma em raízes e radículas. Organizou, estabilizou, neutralizou as multiplicidades segundo eixos de significância de subjetivação que são os seus. Ele gerou, estruturalizou o rizoma, e o decalque já não reproduz senão ele mesmo quando crê reproduzir outra coisa. Por isso ele é tão perigoso. Ele injeta redundâncias e as propaga. O que o decalque reproduz do mapa ou do rizoma são somente os impasses, os bloqueios, os germes de pivô ou os pontos de estruturação (DELEUZE; GUATTARI, 1995, p. 23).

Embora já acenado no texto, destacamos o papel das linhas. As linhas dentro de um rizoma são elementos que comportam em seu devir o rompimento da dicotomia uno/múltiplo; as linhas de um rizoma são, portanto, uma multiplicidade, pois cada linha se constitui ou carrega a heterogeneidade. Deleuze, em Diálogos (1998), afirma que as linhas são os elementos constitutivos das coisas e dos acontecimentos: "indivíduos ou grupos, somos feitos de linhas, e tais linhas são de natureza bem diversa" (DELEUZE; PARNET, 1998, p. 101.).

Segundo Deleuze, há linhas que foram contornos, configurando objetos, pessoas e situações, assim como há linhas totalmente abstratas. As primeiras são segmentaridade dura, tais como família, profissão, trabalho, aposentadoria. Estas operam no plano molar e são bem determinadas em todas as direções. Há outras linhas de segmentaridade mais flexíveis, que operam no plano molecular, e, de alguma forma, provocam modificações, desvios, rompem com contornos estabelecidos, delineiam quedas ou impulsos. Muitas coisas se passam sobre essa segunda espécie de linhas, devires, microdevires, de ritmos diferentes. Há também as 
linhas de fuga, consideradas abstratas: são as mais complicadas de todas e as mais tortuosas. Essas linhas são imanentes umas às outras, misturadas umas nas outras. Ainda um belo texto deleuziano sobre as linhas:

Indivíduos ou grupos somos atravessados por linhas, meridianos, geodésicas, trópicos, fusos, que não seguem o mesmo ritmo e não têm a mesma natureza. São linhas que nos compõem, diríamos três espécies de linhas. Ou, antes, conjuntos de linhas, pois cada espécie é múltipla. Podemos nos interessar por uma dessas linhas mais do que pelas outras, e talvez, com efeito, haja uma que seja, não determinante, mas que importe mais do que as outras... [...] Pois todas essas linhas, algumas nos são impostas de fora, pelo menos em parte. Outras nascem um pouco por acaso, de um nada, nunca se saberá por quê. Outras devem ser inventadas, traçadas, sem nenhum modelo nem acaso: devemos inventar nossas linhas de fuga se somos capazes disso, e só podemos inventá-las traçando-as efetivamente, na vida (DELEUZE; GUATTARI, 2012, p. 83).

As linhas de fuga não se caracterizam, evidentemente, por uma mera fuga do mundo, mas, antes, em fazê-lo fugir. Trata-se, pois, de pensar as possibilidades de saída de sistemas de opressão, sejam eles quais forem. No processo da construção da linha, é possível encontrar armas novas para opô-las às pesadas armas do Estado, esclarecem os autores.

A modo de fechamento de tópico, trazemos um texto lapidar e que marca uma característica do pensamento rizomático:

Um rizoma não começa nem conclui, ele se encontra sempre no meio, entre as coisas, inter-ser, intermezzo. A árvore é filiação, mas o rizoma é aliança, unicamente aliança. A árvore impõe o verbo "ser", mas o rizoma tem como tecido a conjunção "e... e... e..." Há nesta conjunção força suficiente para sacudir e desenraizar o verbo ser (DELEUZE; GUATTARI, 2011, p. 48).

O rizoma encontra-se sempre no meio, e o meio não significa a média, mas o espaço de fluxo entre as extremidades - como entre as margens de um rio, o lugar onde as coisas atingem velocidade.

Eis, portanto, sucintamente, a proposta rizomática. Ela é uma complexa tentativa de explicitar possibilidades para o conhecimento humano. Seus desdobramentos pertencem à ordem dos devires, dos agenciamentos que formos capazes de desenvolver nos múltiplos espaços de conhecimento, dentre eles, na educação matemática.

O rizoma sugere, portanto, novos trânsitos, novos caminhos que venham quebrar a verticalidade científica e as dinâmicas acadêmicas que se cristalizam e se fossilizam, impedindo, assim, novos fluxos, iniciativas de criação.

\section{Rizomas e utopia}

Decorrente da concepção de rizoma, podemos assinalar alguns tópicos que nos parecem pertinentes aos propósitos deste texto e que poderão ser ampliados na interlocução de um virtual leitor: pensar a educação matemática, a despeito de toda hierarquização eminentemente arbórea, sob ação da fórmula n-1; desterritorializar.

Um tema recorrente e especial é considerarmos o currículo. Pista de corrida, de movimento, o currículo é um espaço-tempo privilegiado para a mediação educativa. Silvio Gallo (2008), vanguardista de incursões no tema, considera a compartimentalização do 
conhecimento contemporâneo e suas consequências para a educação, que sofre com a organização curricular estanque, e propõe pensar a questão não apenas como um problema pedagógico, mas epistemológico. É necessário, segundo o autor, compreender os processos históricos e sociais da produção de saberes, para podermos compreender as possibilidades de organização e produção de saberes na escola, na academia. Ao incursionar sobre o tema, o autor confronta o paradigma arborescente com a perspectiva rizomática.

Como vimos, o rizoma rompe com a hierarquização, tanto na dimensão do poder quanto na circulação de conhecimento, peculiar ao modelo arbóreo. No rizoma, são possíveis múltiplas linhas de fuga e, desse modo, múltiplas possibilidades de conexões, abordagens, devires. Rompendo com a hierarquia sedimentada, o rizoma pede, porém, uma nova forma de trânsito possível, e podemos encontrá-la, conforme o filósofo brasileiro, na transversalidade. Esse conceito foi criado pelo filósofo Félix Guattari e pode ser aplicado à imagem rizomática do saber: "ela seria a matriz da mobilidade por entre os liames do rizoma, abandonando os verticalismos e horizontalismos que seriam insuficientes para uma abrangência de todo o horizonte de eventos possibilitados por um rizoma" (GALLO, 2008, p. 79).

As propostas de interdisciplinaridade postas nos ambientes acadêmicos apresentamse hoje de modo limitado: não quebram as verticalidades. Já a transversalidade rizomática aponta para a transversalidade do saber, possibilitando trânsitos mais abrangentes no saber científico; ela aponta para o reconhecimento da multiplicidade, para a atenção às diferenças e à diferenciação, construindo trânsitos alternativos para a multiplicidade dos conhecimentos.

Em termos de organização curricular da escola, a perspectiva rizomática "significaria uma revolução no processo educacional, pois substituiria um acesso arquivístico estanque ao conhecimento" (GALLO, 2008, p. 80). A nosso ver, daqui decorre uma pauta educativa que nos parece abandonada na academia, a saber, o debate sobre o problema da disciplinarização do conhecimento e as propostas de encaminhamentos que perpassam a inter-, a poli-, a multi- e a transversalidade. Os modismos que nos avassalam de tempos em tempos tendem a secundarizar e mesmo obliterar o tema, como se já estivesse resolvido. Ora, como educadores e alunos, temos direito de reenfrentar esse problema. Isso implica em reencaminhar esforços que possam desbloquear, alterar nossa organização curricular, nossas visões de mundo, de ciência e de ensino. Perguntamo-nos se esse não continua sendo um dos maiores desafios a enfrentar na formação inicial e contínua em nossas licenciaturas e bacharelados em matemática. Gastamos tempo demais com normatizações, e um conjunto de prescrições legais que tomam o tempo e as energias dos professores no seu cotidiano. O resultado é conhecido. Repetem-se os velhos modelos organizacionais, curriculares, metodológicos, pois eles fornecem uma certa segurança, embora permaneçam no universo da representação, ou seja, do paradigma arbóreo.

Romper com a compartimentalização das gavetas é uma tarefa que não acaba nunca, e, no contexto rizomático, a educação poderia possibilitar a cada aluno um acesso diferenciado às áreas do saber de seu interesse. Viabilizar conexões é o desafio. Evidentemente, isso significaria, como assinala o filósofo brasileiro, recriar, reinventar a escola, a universidade. É um convite a uma aventura fantástica de criação.

Acrescentamos ainda outros questionamentos: se múltiplas conexões podem ser realizadas na perspectiva rizomática, por que ousamos tão pouco? Uma timidez epistêmica nos bloqueia. Quando romperemos com as convicções arraigadas da disciplinarização, que frequentemente secundarizam os conhecimentos e as conexões com as ciências humanas, por 
exemplo? Quando levantaremos suspeita sobre nossas metodologias, modos de ensinar, que já caducaram faz tempo? Quando virá o dia em que as propostas curriculares para os cursos de matemática se articularão considerando, além dos conhecimentos específicos da área, outras formas de conhecimento, como a arte e seus infinitos movimentos no caos da criação? Que loucura, dirão muitos! Todavia, como assinala Gallo (2008), já houve momentos em que, na história humana, parecia loucura lançar-se aos mares para além do continente conhecido ou lançar-se ao espaço almejando a lua.

Como constatamos, o conhecimento rizomático reluz fortemente na dimensão da conexão, da multiplicidade, todavia é importante assinalar que há incontáveis vetores despotencializadores; aliás, do rizoma podem brotar árvores, emergir multiplicidades falsas. Entendemos que as conexões na educação devem ser efetivadas considerando também as linhas molares de poder. Nas bordas fronteiriças do conhecimento, o pensamento disciplinar arbóreo se protege com cercas epistêmicas espinhentas, como as de arame farpado. Ora, sem uma radical abertura política e o cultivo de uma cultura científica e acadêmica fundamentalmente democrática, pouco avançaremos.

Com efeito, a educação em geral - enquanto campo aberto - tem sido loteada e povoada por todo tipo de interesse, no qual o universo da opinião efetivamente se exibe adotando trajes de realeza, tal como o rei vaidoso de Christian Andersen ${ }^{3}$. Diante da ambição do rei e da esperteza dos embusteiros - vendedoras de roupas invisíveis - , a história nos narra uma situação insólita na qual o rei acaba desfilando pelado numa manifestação popular, até que uma criança desmascara a situação com um grito: "o rei está nu!" Ao que todos os súditos ecoam: "sim, o rei está nu".

Sim, o devir-criança manifesta que o rei está nu na educação matemática quando temos medo de ousar e apenas reproduzimos propostas curriculares engessadas, disciplinarizadas, fruto de concepções arbóreas; está nu quando na academia se criam disciplinas "frankenstein" para cumprir as regulamentações absurdas, mas sem nenhum rosto definido; o rei está nu quando o séquito dos gestores se submete ao faz de conta governamental diante da educação; o rei está nu quando professores se digladiam nas relações de micropoder; o rei está nu quando os discursos politicamente corretos da educação impingem fardos inexequíveis ao trabalho do professor; o rei está nu quando colegas de trabalho viram patrões; o rei está nu quando o produtivismo neotecnicista invade as práticas de pesquisa, tornando-as estéreis; o rei está nu, quando professores publicam dezenas de artigos para brilhar no currículo lattes, mas são incapazes de promover vivências de sabedoria; está nu quando os discursos filisteus intentam silenciar vozes dissonantes e alternativas; o rei está nu quando a lógica do sistema, condenada pela maioria, é reproduzida com volúpia nas seções dos intocáveis. Enfim, o rei está nu quando continuamos a procurar a identidade única da educação matemática.

De fato, temos muitos desafios para enfrentar. Nossos espaços-tempos educacionais estão contaminados historicamente pelas segmentações, hierarquias, mecanismos de controle alinhados com perspectivas políticas retrógradas. Facilmente cedemos ao

\footnotetext{
3 (1805-1875): escritor dinamarquês que gostava de contar histórias, dentre elas, a história do rei que se deixou enganar ao adquirir roupas fictícias que tinham a peculiaridade de parecer invisíveis às pessoas destituídas de inteligência ou àquelas que não estavam aptas para os cargos que ocupavam. O rei deixou-se levar pelos tecelões embusteiros e por sua corte, que se omitiu, e acabou por desfilar nu no meio do povo de seu reino, até que uma criança gritou e desmascarou a farsa gritando: o rei está nu.
} 
pragmatismo cínico, calculista e de horizontes curtos. Por isso, o convite para pensar rizomaticamente a educação e, por extensão, a educação matemática, pode soar utópico, como reconhece Gallo (2008). De fato, naturalizamos hábitos, estruturas organizacionais, metodologias que nos impedem de ousar. Por isso mesmo, entendemos que as iniciativas que porventura venham a se inspirar na educação rizomática em nada se envergonham de serem consideradas utópicas.

Referindo-se à utopia, Peter Pál Pelbart, profundo estudioso de Deleuze, assinala as dificuldades do termo, mas esclarece que a utopia em Deleuze jamais remete a um tempo futuro e a uma forma ideal. Designa, antes, "o encontro entre o conceito e o meio presente, entre um movimento infinito e o que há de real aqui e agora, que o estado de coisas impedia de vir à tona" (PELBART, 2020).

Portanto, explorar as possibilidades do presente é um modo de compreendermos os desafios contemporâneos que envolvem toda a educação matemática. Aqui fazemos uma digressão, ou melhor, uma desterritorialização, evocando a contribuição de Boaventura de Souza Santos, ao pensar o conceito de utopia no contexto de um paradigma científico emergente:

A utopia é a exploração de novas possibilidades e vontades humanas, por via da oposição da imaginação à necessidade do que existe, só porque existem em nome de algo radicalmente melhor que a humanidade tem o direito de desejar e por que merece a pena lutar. A utopia é uma chamada de atenção para o que não existe como (contra) parte integrante, mas silenciada, do que existe (SANTOS, 1997, p. 324).

O autor desloca o sentido tradicional de uma utopia passiva e idealizada para uma utopia vibrante, que inclui o desejo, a paixão, a subjetividade. Para Santos (1997), as duas condições de possibilidade de utopia são uma nova epistemologia e uma nova psicologia. Como nova epistemologia, a utopia recusa o fechamento do horizonte de expectativas e de possibilidades e procura criar alternativas na produção do conhecimento; como nova psicologia, a utopia recusa a subjetividade associada ao conformismo e estimula a vontade de lutar por alternativas, sem mistificações de qualquer espécie.

Portanto, parece-nos que a educação rizomática nos permitiria sondar o passado para compreendê-lo, mas olhar para as possibilidades que se alojam no presente, intensificando a vida e, com ela, a educação. Todavia, como nova psicologia que recusa a subjetividade conformista, é necessário ponderar que não basta criar novos conhecimentos, é mister que as pessoas neles se reconheçam e deles se apropriem, pois "de nada valerá inventar alternativas de realização pessoal e coletiva, se elas não são apropriáveis por aqueles a quem se destinam" (SANTOS, 1997, p. 333).

Isso implica na necessidade permanente de diálogo criativo entre as propostas da educação matemática. Implica, ainda, não desconsiderar a contínua tensão e vinculação entre processos formativos e o lugar social de quem se forma; entre educação, conhecimento, sociedade e política.

À guisa de finalização, assinalamos que a educação rizomática permanece como um conceito a ser explorado na medida em que nos faz pensar sobre os acontecimentos que nos sucedem e nos encoraja, também, a assumir encaminhamentos. Um deles é que os professores que atuam na educação matemática, para além dos horizontes engessados de uma educação tradicional falida, assumam a sua própria incompletude e contingencialidade, 
sem abrir mão da construção de linhas de fugas, micropolíticas existenciais nos espaçostempos onde atuam.

\section{Referências}

ALLIEZ, Eric. Deleuze Filosofia Virtual. São Paulo: Editora 34, 1996.

CAPRA, Frijof. A Teia da Vida: uma nova compreensão científica dos sistemas vivos. Tradução de Newton Roberval Eichemberg. 1. ed. São Paulo: Cultrix, 2012.

DA SILVA, Tomaz Tadeu; KOHAN, Walter. Dossiê Deleuze. Educação \& Sociedade, Campinas, v. 26, n. 93, p. 1171-1182, set./dez. 2005. Disponível em: http://www.cedes.unicamp.br. Acesso em: 14 dez. 2012.

DELEUZE, Gilles. Em que a filosofia pode servir à matemática e mesmo a músicos. Educação e Realidade, v. 27, 2002. Disponível em:

https://seer.ufrgs.br/educacaoerealidade/article/view/31078/19290.

DELEUZE, Gilles. Diferença e repetição. Tradução de Luiz Orlandi e Roberto Machado. Rio de Janeiro: Graal, 2006.

DELEUZE, Gilles; GUATTARI, Felix. Mil Platôs. Capitalismo e Esquizofrenia. Tradução de Ana Lúcia de Oliveira e Lúcia Cláudia Leão. 2. ed. São Paulo: Ed. 34, 2011. v. 1.

DELEUZE, Gilles; GUATTARI, Felix. Mil Platôs. Capitalismo e Esquizofrenia. Tradução de Ana Lúcia de Oliveira e Lúcia Cláudia Leão. 1. ed. São Paulo: Ed. 34, 1995. v. 2.

DELEUZE, Gilles; GUATTARI, Felix. Mil Platôs. Capitalismo e Esquizofrenia. Tradução de Aurélio Guerra Neto, Ana Lúcia de Oliveira, Lúcia Cláudia Leão e Suely Rolnik. 2. ed. São Paulo: Ed. 34, 2012. v. 2.

DELEUZE, Gilles; GUATTARI, Félix. O que é a filosofia? Tradução de Bento Prado Jr. e Alberto Alonso Munôz. 2. ed. Rio de Janeiro: Ed. 34, 1997.

GALLO, Silvio. Deleuze \& a Educação. 2. ed. Belo Horizonte: Autêntica, 2008.

LISPECTOR, Clarice. A hora da estrela. 23. ed. Disponível em: https://descomplica.com.br/gabaritoenem/questoes/2013/segundo-dia/tudo-no-mundo-comecou-com-um-sim-uma-molecula-dissesim/. Acesso em: 18 nov. 2020.

MORIN, Edgar. A cabeça bem-feita: repensar a reforma, reformar o pensamento. Rio de Janeiro: Bertrand Brasil, 2014.

PELBART, Peter Pál. Gilles Deleuze e a utopia imanente. Disponível em: https://revistacult.uol.com.br/home/a-utopia-imanente/. Acesso em: 29 jul.2020.

REALE, Giovanni; ANTISERI, Dario. História da Filosofia. 4. ed. São Paulo: Paulus, 1990. v. 2, 3.

SANTOS, Boaventura de Souza. Pela mão de Alice: o social e o político na pós- modernidade. 3. ed. São Paulo: Cortez, 1997. 
SCHNEIDER, Daniela da Cruz. Da árvore ao rizoma: possibilidades para o campo educacional. Revista Partes. São Paulo, 2014. Disponível em: https://www.partes.com.br/2014/02/01/da-arvore-aorizoma-possibilidades-para-o-campo-educacional/. Acesso em: 3 ago. 2020.

ZOURABICHVILI, François. O vocabulário de Deleuze. Tradução de André Telles. Digitalizado por Cienti-IFCH Unicamp. Disponível em: https://escolanomade.org/wp-content/downloads/deleuzevocabulario-francois-zourabichvili.pdf. Acesso em 25 jul. 2020. 